\title{
EFFORTS TO REDUCE FOOD LOSS IN RESTAURANTS AND TO ASSESS CONSUMER AWARENESS IN JAPAN
}

\author{
MIZUHO SATO ${ }^{1}$, KYOKA HATTA ${ }^{1}$, WAKANA HIGUCHI ${ }^{1}$, TAKEHIRO HAYASHIDA $^{1}$, \\ KAZUHIKO HOTTA ${ }^{1} \&$ SHAHLA M. WUNDERLICH ${ }^{2}$ \\ ${ }^{1}$ Tokyo University of Agriculture, Food Environment Economic, Japan \\ ${ }^{2}$ Montclair State University, Nutrition and Food Science, USA
}

\begin{abstract}
The amount of food waste in Japan is extremely high. In 2016, food waste generated by the food industry was 27.59 million tons. The breakdown is as follows: 16.17 million tons from food manufacturers, 270,000 tons from food wholesalers, 1.27 million tons from food retailers, and 1.99 million tons from restaurants, while consumers wasted 7.89 million tons. This means that about 6.43 million tons of food is lost (i.e. food that can be eaten has been thrown out). The total restaurant food waste rate is approximately $10 \%$ of which only $23 \%$ is recycled. Recycled food from restaurants is turned into fertilizer and feed. The main reasons for food waste in restaurants are leftovers and overstocking. As there are many different types of food restaurants in Japan, there has been little research on food loss reduction. We interviewed 15 restaurants and conducted a survey of consumers' awareness about food waste and loss. The results indicated that the most common cause of food loss was leftover foods. Therefore, many restaurants in Japan try to reduce food loss by offering "doggy bags" as a means for consumers to take leftover foods home. However, it is difficult to accept doggy bags in Japan. Consumers are becoming more conscious of food loss thus many are willing to take leftover food if there is an established and acceptable system. However, a small number of consumers said they did not want to take the leftover foods home, because if they live alone, they may use it and they end up discarding it. To promote doggy bags to reduce food loss in restaurants, may be necessary to improve communications between providers (restaurants) and consumers. In addition, at university restaurants like big cafeterias, there were many unsold foods. Thus, using the food share application for unsold foods is one tool to help reduce food waste, and some consumers want to use this food share application.
\end{abstract}

Keywords: food loss, restaurant, consumer behavior, leftover food, food share application.

\section{INTRODUCTION}

Roughly one-third of the edible parts of food produced for human consumption gets lost or wasted globally, which is about 1.3 billion tons per year [1]. At the regional level, estimates range from 5-6 percent in Australia and New Zealand to 20-21 percent in Central and Southern Asia [1]. In terms of food groups, roots, tubers, and oil-bearing crops are reported to have the highest levels of loss, followed by fruits and vegetables [1]. The cause of the waste of agricultural products are non-standard products such as those that are disfigured, scratched, and of poor quality during their distribution. The "2030 Agenda for Sustainable Development" (the 2030 Agenda) is a set of international development goals to be achieved by 2030, which was adopted at a UN summit in September 2015. The 2030 Agenda sets out SDGs consisting of 17 goals and 169 targets that are interrelated and closely linked to each other. One of the goals is "Responsible Consumption \& Production," and the goal is to halve the levels of food waste globally in retail and consumption [2]. It is important to reduce food waste for a sustainable society.

Until now, various studies have been conducted on reducing food waste. For example, research suggests that it is important to educate employees and devise sales methods at food supermarkets [3] and use food banks to reduce unsold food at supermarkets or factories [4]. Authors have also clearly demonstrated that efforts on food waste reduction in the food 
industry may be made by improving the food label [5]. On the other hand, there is not much research on how to reduce food waste at restaurants and university cafeterias. The causes of food waste at restaurants and university cafeterias can be broadly divided into three categories: food waste when cooking, food not served, and leftover food by consumers. Waste of ingredients during cooking is often due to mistakes in the order quantity or when there are fewer visitors than expected, among others. If the ingredients can be used for other dishes or menus on another day, these items will not go to waste. However, chain stores may also produce more food waste when they do not have a fixed menu or strictly controlled ingredients. In addition, the dishes already made but not served cannot be sold at a discount like supermarket items, and consumers are also not allowed to bring home leftover foods because of hygiene issues. Therefore, they often go to waste at restaurants. Communication between the restaurant employees and consumers is important. Kobayashi et al. conducted a survey of food waste at restaurants (pubs, fast food (Japanese/Western)) by dividing them into food loss, cooking waste, leftover foods, and unsold foods. As a result, there were many leftover foods in all restaurants, pointing out that it was difficult when only corporate efforts were made [6]. Al-Domi et al. compared wasted school meals with students' personal information in Jordan. The results showed that much of the rice was wasted. This is because students from low-income families tend to choose the low-cost menu, and if the servings of rice are too large for them, there will be leftovers. Therefore, he pointed out that the amount of servings for the students' meals should be considered at the university cafeteria [7]. Takahashi et al. also conducted research on food waste at a university cafeteria in Japan and considered reduction methods [8]. The results of the research showed that $16 \%$ of the food waste were leftover foods, and $84 \%$ were unsold foods; thus, there were more unsold foods than leftover foods at the university cafeteria. About $97 \%$ (7,122 g/day) of unsold foods were reduced by two methods: "refrigerated white rice, and provided it the next day" and "purchased by employees." They pointed out that these methods were effective for reducing the waste from unsold food at the university cafeteria. Boschini et al. conducted a large-scale survey of the food waste of 78 school cafeterias in Italy [9]. Results showed that the causes of food waste were related to the breads served before meals, the meal servings, the location of the kitchen, the meals served during the morning break, the menu composition, and the geographical location of the school [9]. This indicates that volume was one of the reasons of food waste at university cafeterias. Boschini et al. conducted a preliminary survey before conducting a large-scale survey [10]. The method was divided into three steps based on the sources of food waste: cooking waste from ingredients, food leftovers, and uneaten dishes. As a result, uneaten dishes were the highest source of waste in school meals. However, no specific reduction method has been investigated.

This study investigates a method of reducing food waste at restaurants (university cafeterias), particularly the effect of the food sharing application that has recently become popular [11]. The food share application is a system wherein the provider (restaurant or shop people) posts the surplus food on the internet to allow purchasers to buy it. However, the provider and the consumer must install the food share application in advance. Doing so may be an additional work for the provider, but if using the application would lead to a reduction in food waste, the use of food share applications will spread throughout the world and food waste will reduce dramatically. A survey was also conducted on consumer awareness of food waste (especially, food waste in restaurants). Based on the opinions of both the provider and the consumer, we decided to consider ways to reduce food waste in restaurants (including those of universities) that are acceptable to consumers. 


\section{METHODS}

\subsection{Interview of the restaurants around Tokyo, Japan}

An interview survey was conducted in the restaurants of Tokyo from September 30 to October 6,2019. Interviews were conducted with 15 restaurants, both private and chain stores (including franchises). The interview included the current situation of the food waste at the restaurant, their actions on reducing food produced, and the means of reducing leftover foods.

\subsection{Effect of using the food sharing application in university cafeterias}

The university cafeteria where the survey was conducted is located in Tokyo, and it opens from 10:30 a.m. to $8 \mathrm{pm}$. During the period when the university is closed (August, September, February, March), the cafeteria opens only from 10:30 am to $2 \mathrm{pm}$. People who come to eat in the university cafeteria are not only students but also other locals. The university cafeteria tried to use the food share application from October 1, 2019, so we collected this data from October 1, 2019 to February 29, 2020.

\subsection{Awareness of food waste among Japanese citizens}

A survey was distributed, and responses were collected by e-mail or in writing during the research study period from November 5 to November 16, 2019. 106 Japanese men and women over the age of 10 completed the survey. The response rate was $98 \%$, with $45.8 \%$ of the respondents identifying themselves as women, and 55.2\% as men. Half the respondents, or $42.5 \%$, were aged $20-29,24.5 \%$ were $10-19,8.5 \%$ were $30-39,7.5 \%$ were $40-49,11.3 \%$ were $50-59$, and $5.7 \%$ were over 60 years old. $3.8 \%$ were self-employed, $1.9 \%$ were from the faculty, $17.1 \%$ were company employees, $12.4 \%$ were part-time workers, and $64.8 \%$ mostly students, among others. The number of households were $34.9 \%$ for singles, $14.2 \%$ for couples, $43.4 \%$ for those with 2 households, $1.9 \%$ for 3 households, and $5.7 \%$ for others.

\section{RESULTS}

\subsection{Interview of the restaurants around Tokyo in Japan}

The results of the interview are shown in Tables 1 and 2. The average operating hours of private restaurants were about 9 hours. We asked the top three causes of the food waste at the restaurants, and the results show that the main sources of food waste were garbage, leftover foods, and unused items such as vegetables, rice, noodles, and the like. As a method of reducing leftover foods in private restaurants, they were usually taken home, and the unused items were used for employee meals.

On the other hand, the average opening hours of franchises and chain stores are about 11 hours, which is slightly longer than private restaurants since this category includes pubs. Similarly, the main causes of food waste were garbage, leftover foods, and unused items, with the same method of reducing leftovers as private restaurants. However, some of the franchises and chain stores are not allowed take the leftover foods home, and were thus wasted at the restaurants. The reason was also to prevent food poisoning and complaints because some people came from far away.

Employees' awareness of food loss was $80.0 \%$, including "well conscious" and "somewhat conscious," indicating a high level of employee awareness of food loss (Fig. 1). Therefore, when taking a customer's order, they advise them not to order too much food. 
Table 1: The result of interview of the private restaurants.

\begin{tabular}{|c|c|c|c|c|c|}
\hline $\begin{array}{l}\text { Name of the } \\
\text { restaurant }\end{array}$ & $\mathrm{A} 1$ & $\mathrm{~A} 2$ & A4 & A5 & A8 \\
\hline $\begin{array}{l}\text { Type of the } \\
\text { restaurant }\end{array}$ & $\begin{array}{c}\text { Private } \\
\text { restaurant }\end{array}$ & $\begin{array}{c}\text { Private } \\
\text { restaurant }\end{array}$ & $\begin{array}{l}\text { Private } \\
\text { restaurant }\end{array}$ & $\begin{array}{c}\text { Private } \\
\text { restaurant }\end{array}$ & $\begin{array}{c}\text { Private } \\
\text { restaurant }\end{array}$ \\
\hline \multirow[b]{2}{*}{ Open time } & $\begin{array}{c}11: 30 \mathrm{am}- \\
2: 30 \mathrm{pm}\end{array}$ & $\begin{array}{l}11: 30 \mathrm{am}- \\
2: 30 \mathrm{pm}\end{array}$ & $\begin{array}{c}11: 30 \mathrm{am}- \\
3: 00 \mathrm{pm}\end{array}$ & $\begin{array}{c}11: 30 \mathrm{am}- \\
3: 00 \mathrm{pm}\end{array}$ & $\begin{array}{l}11: 30 \mathrm{am}- \\
3: 00 \mathrm{pm}\end{array}$ \\
\hline & $\begin{array}{l}5: 00 \mathrm{pm}- \\
10: 00 \mathrm{pm}\end{array}$ & $\begin{array}{l}5: 00 \mathrm{pm}- \\
10: 30 \mathrm{pm}\end{array}$ & $\begin{array}{c}\text { Sat: } \\
\text { 5:00pm- } \\
\text { 11:00pm } \\
\text { Sun: } \\
\text { 5:30pm-- } \\
\text { 11:00pm }\end{array}$ & $\begin{array}{l}\text { 4:30pm- } \\
\text { 9:30m } \\
\text { Sun: } \\
\text { 4:30pm- } \\
\text { 8:30pm }\end{array}$ & $\begin{array}{l}5: 00 \mathrm{pm}- \\
11: 00 \mathrm{pm}\end{array}$ \\
\hline $\begin{array}{l}\text { The reason of } \\
\text { the food waste } \\
\text { (Top 3) }\end{array}$ & $\begin{array}{c}\text { Garbage, } \\
\text { Leftover } \\
\text { foods }\end{array}$ & $\begin{array}{c}\text { Garbage, } \\
\text { Pass expiration } \\
\text { date, } \\
\text { Leftover foods }\end{array}$ & Garbage & $\begin{array}{l}\text { Garbage, } \\
\text { Leftover } \\
\text { foods }\end{array}$ & $\begin{array}{l}\text { Leftover } \\
\text { foods, } \\
\text { Order miss }\end{array}$ \\
\hline $\begin{array}{l}\text { The way of } \\
\text { reducing food } \\
\text { waste }\end{array}$ & $\begin{array}{l}\text { We try } \\
\text { not to } \\
\text { cook too } \\
\text { much }\end{array}$ & - & $※ 1,3$ & $※ 1$ & $※ 1$ \\
\hline Take away $* 4$ & $\circ$ & ○ & $\Delta$ & $\Delta$ & $x$ \\
\hline
\end{tabular}

$※ 1$ : The dishes that were overcooked and could not be served is used for employee meals

$※ 2$ : The leftover foods are wasted

$※ 3$ : If there is excess food, make a new menu

$※ 4$ : They allow take away of leftover foods to home $\circ$

They allow take away of leftover foods to home for only regular customers $\Delta$

They do not allow take away of leftover foods to home $x$

Table 2: Interview results from franchises and chain restaurants.

\begin{tabular}{|c|c|c|c|c|c|}
\hline $\begin{array}{l}\text { Name of the } \\
\text { restaurant }\end{array}$ & $\begin{array}{l}\text { Type of the } \\
\text { restaurant }\end{array}$ & Open time & $\begin{array}{l}\text { The reason of the } \\
\text { food waste } \\
\text { (Top 3) }\end{array}$ & $\begin{array}{l}\text { The way of } \\
\text { reducing food } \\
\text { waste }\end{array}$ & Take away $^{\star 4}$ \\
\hline A3 & Franchises & $\begin{array}{c}11: 30 \mathrm{am}- \\
3: 00 \mathrm{pm} \\
5: 00 \mathrm{pm}- \\
11: 00 \mathrm{pm}\end{array}$ & $\begin{array}{l}\text { Garbage, } \\
\text { Too much } \\
\text { Preparation, } \\
\text { Leftover foods }\end{array}$ & $※ 1$ & $x$ \\
\hline A6 & Chain stores & $\begin{array}{l}5: 00 \mathrm{pm}- \\
12: 00 \mathrm{am}\end{array}$ & $\begin{array}{c}\text { Garbage, } \\
\text { Left-over foods, } \\
\text { Order miss }\end{array}$ & - & o \\
\hline B1 & Chain stores & $\begin{array}{c}5: 00 \mathrm{pm}- \\
\text { 5:00am }\end{array}$ & $\begin{array}{c}\text { Garbage, } \\
\text { Pass Expiration date, } \\
\text { Left-over foods }\end{array}$ & $※ 1$ & $\times$ \\
\hline B2 & Chain stores & $\begin{array}{l}\text { 4:00pm- } \\
1: 00 \mathrm{am}\end{array}$ & $\begin{array}{l}\text { Unsold foods, Garbage, } \\
\text { Left-over foods }\end{array}$ & $※ 1,2$ & $x$ \\
\hline
\end{tabular}


Table 2: Continued.

\begin{tabular}{|c|c|c|c|c|c|}
\hline $\begin{array}{l}\text { Name of the } \\
\text { restaurant }\end{array}$ & $\begin{array}{l}\text { Type of the } \\
\text { restaurant }\end{array}$ & Open time & $\begin{array}{l}\text { The reason of the } \\
\text { food waste } \\
\text { (Top 3) }\end{array}$ & $\begin{array}{c}\text { The way of } \\
\text { reducing food } \\
\text { waste }\end{array}$ & Take away ${ }^{\star 4}$ \\
\hline A7 & Chain stores & $\begin{array}{l}11: 30 \mathrm{am}- \\
2: 00 \mathrm{pm} \\
5: 00 \mathrm{pm}- \\
10: 00 \mathrm{pm}\end{array}$ & $\begin{array}{l}\text { Unsold foods, Garbage, } \\
\text { Leftover foods }\end{array}$ & $\begin{array}{c}\stackrel{※}{*} \\
1,2,3\end{array}$ & o \\
\hline B3 & Franchises & $\begin{array}{c}11: 30 \mathrm{am}- \\
11: 00 \mathrm{pm} \\
\end{array}$ & Leftover foods & $\begin{array}{c}※ \\
1,3 \\
\end{array}$ & o \\
\hline A9 & Chain stores & $\begin{array}{l}11: 30 \mathrm{am}- \\
11: 00 \mathrm{pm}\end{array}$ & $\begin{array}{c}\text { Unsold foods, } \\
\text { Pass Expiration date, } \\
\text { Too much } \\
\text { preparation } \\
\end{array}$ & $※ 3$ & $x$ \\
\hline A10 & Chain stores & $\begin{array}{l}11: 30 \mathrm{am}- \\
11: 00 \mathrm{pm}\end{array}$ & Leftover foods & $※ 1$ & $x$ \\
\hline A11 & Chain stores & $\begin{array}{l}11: 30 \mathrm{am}- \\
11: 00 \mathrm{pm}\end{array}$ & $\begin{array}{c}\text { Unsold foods, } \\
\text { Garbage, } \\
\text { Pass expiration date, } \\
\text { Too much } \\
\text { preparation }\end{array}$ & $※ 3$ & $\times$ \\
\hline A12 & Chain stores & $\begin{array}{l}11: 30 \mathrm{am}- \\
11: 00 \mathrm{pm}\end{array}$ & Pass Expiration date & $※ 3$ & ० \\
\hline
\end{tabular}

$※ 1$ : The dishes that were overcooked and could not be served are used for employee meals

$※ 2$ : The leftover foods go to waste

$※ 3$ : If there is excess food, make a new menu

$※ 4$ : They allow take away of leftover foods to home $\circ$

They do not allow take away of leftover foods to home $\times$

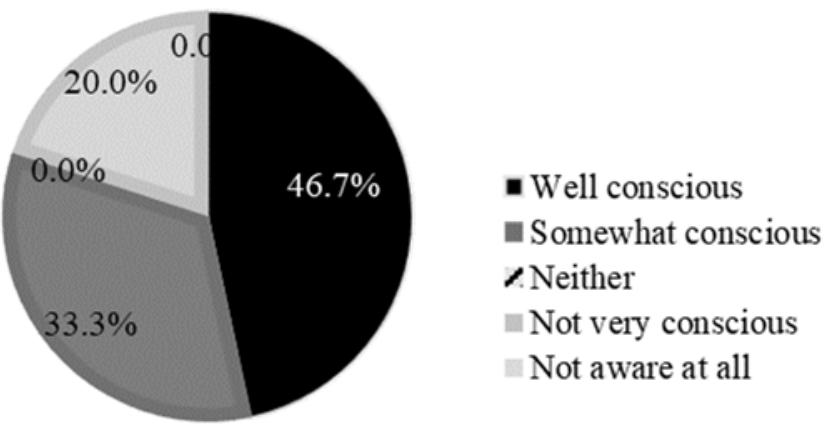

Figure 1: Are you conscious about food loss?

\subsection{Effect of the use of the food sharing application in university cafeterias}

The data of the amount of reduced food waste by using the food share application are shown Table 3. The total amount reduced by using the application was $67,600 \mathrm{~g}$. The period for using the food share application was 54 days; thus, the reduced food waste per day is about $1251.9 \mathrm{~g}$. One dish is about $650 \mathrm{~g}$, which means that almost two dishes per day is equivalent to the reduced food waste per day. 
Table 3: Amount of reduced food waste by using the food share application.

\begin{tabular}{|l|c|c|c|c|}
\hline Month & Open days & $\begin{array}{c}\text { Days of using } \\
\text { food share } \\
\text { application }\end{array}$ & $\begin{array}{c}\text { The number } \\
\text { of dishes }\end{array}$ & $\begin{array}{c}\text { Reduction } \\
\text { amount of foods } \\
(\mathrm{g})\end{array}$ \\
\hline Oct. 2019 & 21 & 17 & 49 & 31,850 \\
\hline Nov. 2019 & 22 & 12 & 11 & 7,150 \\
\hline Dec. 2019 & 15 & 8 & 20 & 13,000 \\
\hline Jan. 2020 & 17 & 10 & 13 & 8,450 \\
\hline Feb. 2020 & 18 & 7 & 11 & 7,150 \\
\hline Total & 93 & 54 & 104 & 67,600 \\
\hline Average & - & - & 1.93 & 1251.9 \\
\hline
\end{tabular}

\subsection{Awareness of food waste among Japanese citizens}

Regarding the frequency of going to restaurants in a week, $9.7 \%$ do not go to restaurants often, $61.2 \%$ go $1-3$ times, $23.3 \%$ go $4-6$ times, $3.9 \%$ go $7-9$ times, and $1.9 \%$ often go to restaurants frequently. More than half of the respondents went to restaurants 1-3 times a week. Regarding the experience of having leftover foods at restaurants, the responses showed that $17.0 \%$ said "Yes I have," 37.7\% said "Sometimes," $45.3 \%$ said "No I have never," and $0.0 \%$ said "I do not know" (Fig. 2). About half of the respondents are university students studying the food economy. Therefore, they have little leftovers in their everyday meals.

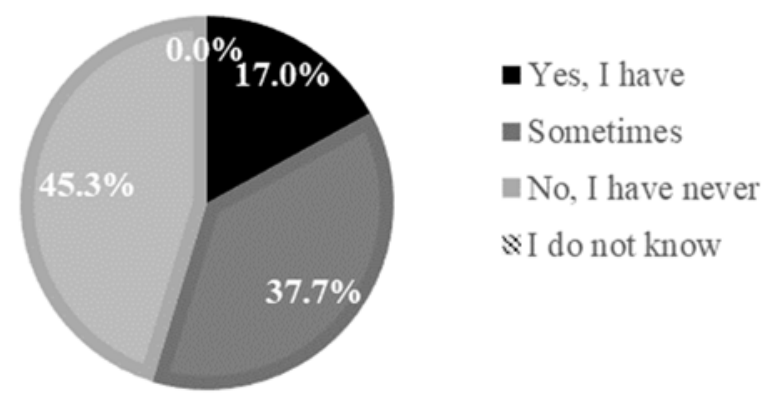

Figure 2: Have you ever had leftover foods at restaurants?

In addition, we asked the respondents if they had left over food and the reason for such leftovers. Among their responses, 46.3\% were "inadequate amount," $22.0 \%$ were "over order," $12.2 \%$ were "there were including of foods I hated," and 19.5\% were "not like the taste." In addition, it seems that over ordering of foods occurred when people eat with friends at a drinking party. 3010 activity is one of the activities that help reduce food loss in Japan. This activity can be done when people take 30 minutes from the start of the party and 10 minutes before the end of the party to sit down, without talking, and enjoy a meal. The activity helps reduce over ordering of dishes and leftover foods. So, we asked, "Do you know about the 3010 activity of reducing food waste in Japan?" The responses showed that 25\% said "I 
do not know at all," 47\% said "I do not know," 19\% said "I know a little," and only 9\% answered "I know." Thus, it is also important to spread awareness of such activities.

We asked, "Do you try not to have leftover foods in your usual meals?" Of the responses, $61.3 \%$ were "Yes, I do always keep in mind," 5.8\% were "I am trying a little," $2.8 \%$ were "No, I do not care," and $0.0 \%$ was "Not at all." More than half of the respondents tried to avoid leftover foods (Fig. 3).

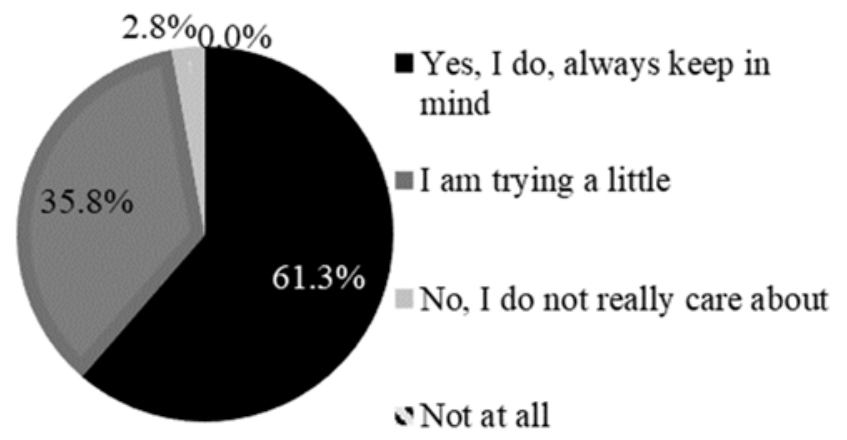

Figure 3: Do you try not to have leftover foods in your usual meals?

In addition, we asked that if you can take away the leftover foods to your home, would you want to? Of the respondents, 50.9\% answered "Yes, I want to take away," $19.8 \%$ answered "sometimes," $28.3 \%$ answered "No, I do not want to take away," and $0.9 \%$ answered "I don't know" (Fig. 4). We also asked the persons who responded that do not want to take away, the reason for such answer. They responded by saying that "I am worried about hygiene and I do not eat it even if I bring it home." Restaurant employees also have concerns about hygiene issues, and it is necessary to clarify the responsibility if something goes wrong.

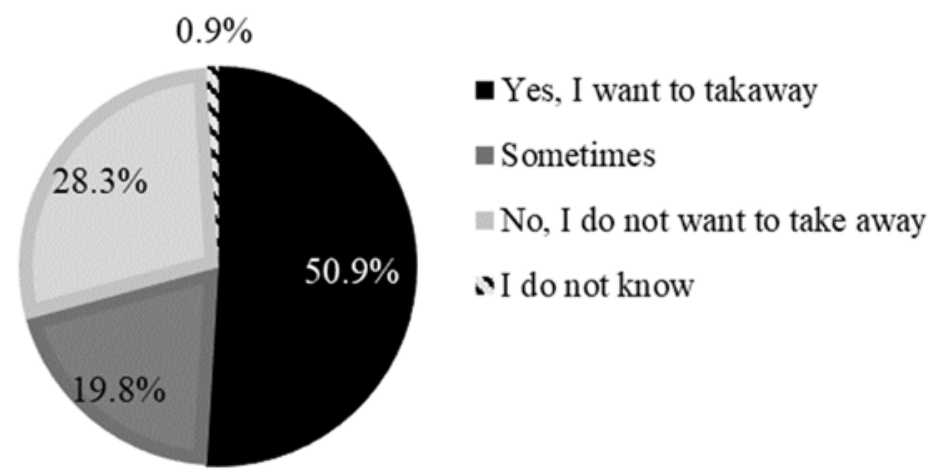

Figure 4: If you can take away leftover foods, would you do so?

Regarding the food share application, we asked the question, "Do you know about the food share application?" and 9.4\% responded "Yes, I know well," 13.2\% said "I know a 
little," 23.6\% said "I do not know much," and 53.8\% responded "I do not know at all." Thus, majority do not know about the food share application (Fig. 5).

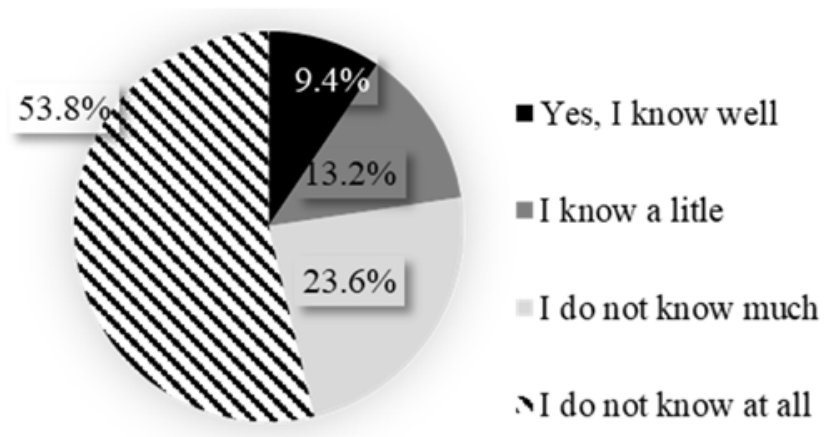

Figure 5: Do you know about the food share application?

Finally, we asked about the method of reducing food waste through a free description. The content was categorized into consumption behavior, purchasing behavior (sales amount, expiration date, etc.), cooking behavior (storage method, plannability, etc.), penalties, technical aspects (applications, IoT, etc.), and the efforts of the food supermarket. As a result, $45.8 \%$ had the highest content of adjusting the amount of consumption behavior, followed by $26.9 \%$ cooking behavior (cooking plan). In addition, some consumers said that they want to use the food share application. Consumers know the way to reduce food waste, but it is difficult for them to act and continue to reduce food waste activities.

\section{DISCUSSION}

As a result of the interviews with employees from various restaurants, it was found that there were many leftover foods and unused items. The private restaurant employee knows the consumer, so it is easy to allow the takeout of leftover foods to their home. However, when the restaurant scale becomes large, it is difficult to understand consumer behavior and they may be more distant, making it difficult to bring leftover foods at home.

Therefore, the activity of eating all meals ordered by consumers is effective for reducing food waste. The 3010 activity is one activity that helps reduce food waste in Japan. People eat the meals during the party at the first 30 minutes and the last 10 minutes without talking. By having time to concentrate on a meal at the party without talking to people, it can avoid leftovers. In Japan, especially for business dinners, food can be left behind even after ordering. With this activity, untouched dishes are not leftover and food waste is reduced. It is important for restaurants, consumers, and local governments to carry out such an activity together because if many local governments join this activity, competition among local governments and the amount of food waste will be reduced.

Many consumers are conscious about food waste. However, $28.3 \%$ of consumers said they did not want to take away leftover foods. In the questionnaire survey, $49.1 \%$ were single and couples. Almost half of the people were from a small family, so even if they take them at home, it will be wasted, because no one eats them. It is especially important to prevent leftover foods in Japan, a country with a declining birthrate and aging population.

In addition, in the interviews of employees from various restaurants, there were not many unsold dishes, but in university restaurants like big cafeterias, there were many unsold foods 
[8], [10]. Thus, using the food share application for unsold foods is one tool to reduce food waste. However, in our survey from the university cafeteria, the average amount of reduced food waste per day is $1251.9 \mathrm{~g}$, which is not a huge amount of food waste reduction. Furthermore, if you use the food share application, you have to pay 150 yen per one meal to the food share application company. This university cafeteria sells each meal at 400 yen, and using the application would only give them a 250 yen profit. The cafeteria employee did say that by using the food share application, they try to think deeper about the food waste problem and start other ways of reducing food waste through an original method. The original way is "Omakase-mori," which is a system where packaged foods are sold at the cafeteria to prevent unsold food which would become waste items. The meal would come in two sizes of food box, the large size is $500 \mathrm{~g}$ and the small size is $300 \mathrm{~g}$. This system started last December. In December and January, the total sales volume was 39,500 g sold in 15 days, and thus, 2,633 $\mathrm{g}$ per were sold per day. This means that this is the amount of food waste reduced. Using this system is more effective in reducing food waste than using the food share application. It is very good point that a new reduction system was developed by cafeteria employees.

We think that if multiple restaurants join food share application and local governments supported this system, there will be a greater reduction of food waste from restaurants. The effect of reducing food waste using the food share application is not big, but it is a great way to raise awareness about food waste and to develop unique reduction methods for each restaurant by the employees.

\section{CONCLUSIONS}

As a result of the interviews with restaurant employees in Japan, the main causes of waste were garbage and leftover food. The private restaurants allow take away of leftover foods, but for franchises and chain stores, not every restaurant allows the take away of leftover foods. The reason was to prevent the cause of food poisoning and complaints because some people came from far away.

Even if they can take away leftover foods, some do not prefer to do so because they worry about hygiene and they do not eat it even if they bring it home. Thus, the 3010 activity is an effective activity for reducing leftover foods, but majority of the people do not know this activity. It is important to spread this activity with the local government.

Consumers are highly aware of food waste and know the way to reduce food waste, but it is difficult to do and continue to reduce food waste activity.

In university restaurants like big cafeterias, there were many unsold foods. Thus, using the food share application for unsold foods is one tool to help reduce food waste, and some consumers want to use this food share application.

The effect of using the food share application is not big, but it is a great way of raising awareness about food waste and to develop unique reduction methods for each restaurant by the employees.

\section{ACKNOWLEDGEMENTS}

The authors want to thank the people in the university cafeteria who participated in the data collection, and the people who participated in the questionnaire survey and interview.

\section{REFERENCES}

[1] Food and Agriculture Organization of the United Nations, Moving Forward on Food Loss and Waste Reduction, The State of Food and Agriculture, 2019. United Nations, Sustainable Development Goals, 2015. 
[3] Sato, M. \& Nakano., M., Analysis of food waste in supermarket store and research for employees an attitude survey for reducing food waste [in Japanese with English summary]. Journal of Japanese Society of Shokuiku, 7(4), pp. 259-283, 2013.

[4] Sato, M. \& Nakano, M., Activity of the Food Bank in Japan and problems based on the viewpoint of Shokuiku Education. Journal of Japanese Education Society, 10(1), pp. 31-40, 2016.

[5] Sato, M. \& Nakano, M., The display on food product influencing the reduction of the amount of food waste. Journal for the Integrated Study of Dietary Habits, 23(3), pp. 166-173, 2012

[6] Kobayashi, T., Ishii, N. \& Miyazaki, K., Analysis of food loss management in food service industry-positioning and development direction as marketing strategy. The Japan Society of Food Service Studies, 18, pp. 24-35, 2013.

[7] Hayder, Al-D., Hiba, Al-R., Fatima A., Safa Y., Rima M. \& Jumana F., Determining and addressing food plate waste in a group of students at the University of Jordan. Pakistan Journal of Nutrition, 10(9), pp. 871-878, 2011.

[8] Takahashi, J., Saito, T. \& Yamakawa, H., Evaluation of food loss reduction efforts at university cafeterias and user acceptability. Proceedings of the 18th Japan Society of Material Cycles and Waste Management, pp. 115-116, 2017.

[9] Matteo, B., Luca, F., Clara, C. \& Silvio, F., Why the waste? A large-scale study on the causes of food waste at school canteens. Journal of Cleaner Production, in press, 246, 2020.

[10] Matteo B., Luca F., Clara C., \& Silvio F. Food waste in school canteens: A reference methodology for large-scale studies. Journal of Cleaner Production, 182, pp. 10241032, 2018

[11] Coccoking Co., Ltd.: TABETE, 2019/2/22. https://www.cocooking.co.jp/. 